Jurnal Kesmas Asclepius

Volume 1, Nomor 1, Juni 2019

e-ISSN : 2684-8287

p-ISSN : 2656-8926

DOI: https://doi.org/10.31539/jka.v1i1.519

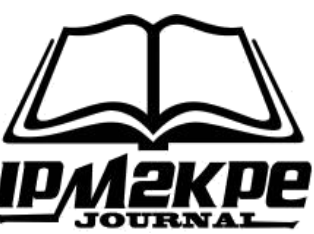

\title{
FAKTOR-FAKTOR YANG MEMPENGARUHI DISIPLIN KERJA KARYAWAN PENUNJANG MEDIS DAN NON MEDIS
}

\author{
Muhammad Amin ${ }^{1}$, Septi Puspita Sari ${ }^{2}$, Abdul Rachman ${ }^{3}$ \\ Universitas Muhammadiyah Bengkulu ${ }^{1,2,3}$ \\ maminumb@gmail.com ${ }^{1}$
}

\begin{abstract}
ABSTRAK
Penelitian ini bertujuan untuk mengetahui faktor - faktor yang berhubungan dengan disiplin kerja karyawan penunjang medis dan non medis Rumah Sakit Khusus Jiwa Soeprapto Provinsi Bengkulu tahun 2017. Jenis penelitian ini adalah penelitian kuantitatif dengan desain penelitian cross sectional. Hasil uji statistik menunjukkan bahwa hubungan antara keteladanan pemimpin terhadap disiplin kerja p-value 0,016 , hubungan antara balas jasa terhadap disiplin kerja p-value 0,000, hubungan antara sanksi hukuman terhadap disiplin kerja dengan p-value 0,009 sedangkan tujuan pekerjaan p-value 0,390 dan kemampuan karyawan dengan p-value 0,375. Simpulan, ada hubungan yang bermakna antara keteladanan pemimpin, balas jasa dan sanksi hukuman terhadap disiplin kerja. Tidak ada hubungan yang bermakna antara tujuan pekerjaan dan kemampuan karyawan dengan disiplin kerja karyawan penunjang medis dan non medis di Rumah Sakit Khusus Jiwa Soeprapto Provinsi Bengkulu.
\end{abstract}

Kata Kunci: Balas Jasa, Disiplin Kerja, Keteladanan Pemimpin, Sanksi Hukuman

\section{ABSTRACT}

This study aims to determine the factors related to the work discipline of medical and non-medical support employees of the Soeprapto Mental Hospital, Bengkulu Province in 2017. This type of research is a quantitative study with a cross sectional research design. The results of statistical tests show that the relationship between exemplary leadership and work discipline p-value 0.016, the relationship between remuneration for work discipline p-value 0,000, the relationship between penalties for work discipline with a pvalue of 0.009 while job objectives p-value of 0.390 and ability employees with a p-value of 0.375. In conclusion, there is a significant relationship between exemplary leaders, remuneration and penalties for work discipline. There is no significant relationship between job goals and employee abilities with the work discipline of medical and nonmedical support employees at Soeprapto Mental Hospital, Bengkulu Province.

Keywords: Remuneration, Work Discipline, Exemplary Leaders, Punishment Sanctions

\section{PENDAHULUAN}

Perkembangan rumah sakit sebagai organisasi pelayanan kesehatan melaju semakin pesat. Rumah Sakit dituntut untuk selalu meningkatkan pelayanannya agar dapat terus bersaing menjadi pilihan masyarakat. Menurut Sitio dalam Sadiah (2015) hal ini dikarenakan semakin tingginya tingkat persaingan antar rumah sakit yang dipengaruhi oleh bertambahnya rumah sakit baru bermunculan, mudahnya masyarakat memperoleh 
informasi, konsumen yang selektif dalam memilih produk kesehatan dan perkembangan ilmu dan teknologi dibidang kesehatan.

Kualitas mutu pelayanan rumah sakit ditentukan dari kualitas sumber daya manusia (SDM) yang tersedia. Dessler (2012) berpendapat bahwa keberhasilan suatu instusi rumah sakit ditentukan oleh dua faktor utama, yaitu sumber daya manusia atau tenaga kerja dan sarana prasarana pendukung atau fasilitas kerja. SDM adalah orang yang bekerja atau menjadi anggota organisasi yang disebut personil, pegawai, karyawan, tenaga kerja, dan lain-lain.

SDM adalah aspek penting dalam suatu organisasi dan perlu digali dan dibangun agar diperoleh sumber daya manusia yang baik. Pengelolaan ini biasa disebut dengan manajemen sumber daya manusia. Manajemen sumber daya manusia adalah ilmu dan seni yang mengatur hubungan dan peranan tenaga kerja agar efektif dan efisien, untuk membantu terwujudnya tujuan perusahaan, karyawan, dan masyarakat (Hasibuan, 2013).

Kualitas sumber daya manusia dapat diukur dari kinerja karyawan dan produktivitasnya. Salah satu tolak ukur untuk mengetahui kinerja karyawan adalah dengan melihat disiplin disamping tingkat pencapaian target, inisiatif, kepatuhan, kesadaran pengembangan diri, loyalitas dan kerjasama kelompok (Anisfuddin, 2001).

Hasibuan (2013) menyatakan ada beberapa faktor yang berhubungan dengan disiplin kerja diantaranya yaitu tujuan dan kemampuan, keteladanan pemimpin, balas jasa, keadilan, pengawasan, sanksi hukuman, ketegasan dan hubungan kemanusiaan. Dalam menjalankan fungsi dan tugasnya, rumah sakit membutuhkan tenaga kerja untuk menjalankan seluruh aktifitas yang ada, sehingga dapat mencapai target-target pekerjaan. Sumber daya manusia yang dimiliki oleh sebuah rumah sakit beranekaragam dan harus mampu bekerja sama agar mampu memberikan pelayanan yang maksimal termasuk kepuasan pada pengguna.

Tenaga medis dan tenaga non medis di rumah sakit menjadi salah satu pelaku organisasi yang profesional. Perilaku ini tidak dilahirkan secara alami, melainkan dibentuk. Seperti tumbuhnya kepemimpinan, pelaku yang akan menjadi professional juga harus melalui beberapa tahap dan dilakukan secara terencana mulai dari tahap pengenalan tentang organisasi dan dunia kerja sampai pada tahap penerapan otonomi dalam pengambilan keputusan. Selain itu juga kedisiplinan sangat menentukan profesionalisme seorang pegawai terhadap kinerjanya. Kedisiplinan pegawai adalah sifat seorang pegawai yang secara sadar mematuhi aturan dan peraturan organisasi tertentu. Kedisiplinan seharusnya dipandang sebagai bentuk latihan bagi pegawai dalam melaksanakan aturanaturan organisasi. Semakin disiplin semakin tinggi produktivitas kerja karyawan dan kinerja organisasi (Handoko, 2012).

Berdasarkan penelitian Nurpeni (2010) menyatakan bahwa salah satu indikator suatu mutu pelayanan rumah sakit adalah sumber daya manusia, karena mutu rumah sakit merupakan cerminan dari semua sistem yang sudah berjalan didalamnya. Selain itu, mutu pelayanan rumah sakit juga merupakan kesesuaian pelayanan dengan standar profesi dengan memanfaatkan sumber daya yang ada secara baik, sehingga semua kebutuhan pelanggan dan tujuan untuk mencapai derajat kesehatan yang optimal dapat tercapai.

Di dalam institusi rumah sakit, Sumber Daya Manusia (SDM) memiliki peranan yang besar dalam pencapaian tujuan atau visi misi dari sebuah rumah sakit yang salah satu diantaranya adalah pencapaian mutu pelayanan rumah sakit. Mutu pelayanan rumah sakit akan baik atau buruk tergantung dari kualitas sumber sumber daya manusia (Sastrohadiwiryo, 2005). 
Berdasarakan penelitian Asniar (2016) disiplin kerja dapat mempengaruhi kualitas baik buruknya kinerja karyawan, adapun salah satu indikator indispliner yang berkaitan dengan disiplin kerja yaitu waktu datang dan pulang kerja tidak tepat pada waktunya. Sehubungan dengan pernyataan di atas, maka salah satu aspek penting yang perlu diperhatikan dalam upaya meningkatkan kualitas sumber daya manusia adalah peningkatan disiplin kerja. Secara sederhana kedisiplinan dipersepsikan jika pegawai tersebut jarang absen dan datang serta pulang tidak tepat pada waktunya.

Asniar \& Tina (2016) menyatakan bahwa disiplin kerja yang baik mencerminkan besarnya tanggung jawab seseorang karyawan terhadap tugas-tugas yang diberikan. Di samping itu disiplin kerja merupakan salah satu indikasi adanya semangat dan kegairahan kerja yang dapat mendukung terwujudnya pencapaian tujuan baik lembaga atau organisasi.

Karyawan Rumah Sakit Khusus Jiwa Soeprapto terdiri dari karyawan medis, paramedis, penunjang medis, penunjang non medis, dan non medis. Karyawan penunjang medis yaitu seperti pada bagian instalasi radiologi, instalasi elektromedik, instalasi gizi, instalasi laboratorium, instalasi farmasi. Karyawan penunjang non medis yaitu instalasi rekam medik dan instalasi PSRS (Profil Rumah Sakit Khusus Jiwa, 2015).

Berdasarkan survey awal yang dilakukan peneliti pada bulan Maret 2017, RSKJ belum memiliki Surat Keputusan Penerapan Sanksi Disiplin Kerja Karyawan (Indisipliner). Hasil wawancara dengan pembinaan dan pengawasan didapatkan masih banyak karyawan penunjang medis dan non medis yang datang terlambat. Selain itu kurangnya disiplin kerja karyawan penunjang medis dan non medis Rumah Sakit Khusus Jiwa juga dapat dilihat dari kurang diterapkannya peraturan rumah sakit, terkait etika dan perilaku karyawan, serta peraturan pemakaian atribut dinas lengkap, masih ada karyawan yang terkadang tidak menerapkan peraturan rumah sakit terkait etika dan perilaku. Pelanggaran-pelanggaran tersebut baik secara langsung maupun tidak langsung dapat menurunkan citra rumah sakit di mata masyarakat.

Berdasarkan rekapitulasi absensi dari seluruh karyawan di rumah sakit tersebut tingkat kejadian keterlambatan yang paling meningkat ada di bagian karyawan penunjang medis dan non medis sedangkan karyawan lain tingkat kejadian keterlambatan rendah.

Penelitian ini bertujuan untuk mengetahui faktor-faktor yang berhubungan dengan disiplin kerja karyawan penunjang medis dan non medis Rumah Sakit Khusus Jiwa Soeprapto Provinsi Bengkulu.

\section{METODE PENELITIAN}

Rancangan penelitian yang digunakan adalah penelitian kuantitatif dengan desain penelitian cross sectional, dimana variabel independen dan variabel dependen diukur dan diamati pada waktu yang bersamaan.

Tujuan penelitian ini adalah untuk mengetahui faktor-faktor yang diteliti yang berhubungan dengan disiplin kerja karyawan penunjang medis dan non medis di Rumah Sakit Khusus Jiwa Soeprapto Provinsi Bengkulu.

Penelitian dilaksanakan di Rumah Sakit Khusus Jiwa Soeprapto Provinsi Bengkulu yang beralamatkan di Jalan Bhakti Husada Lingkar Barat Bengkulu. Penelitian ini dilakukan pada bulan Juli-Agustus 2017.

Populasi dalam penelitian ini adalah seluruh karyawan penunjang medis dan non medis yang aktif bekerja di Rumah Sakit Khusus Jiwa Soeprapto Provinsi Bengkulu. Metode pengambilan sampel yang digunakan yaitu total sampling yaitu seluruh karyawan penunjang medis dan non medis yang berjumlah 84 orang. Jumlah karyawan 
penunjang medis dan non medis tersebut adalah sebanyak 84 orang. Dalam penelitian ini, Peneliti menggunakan 2 (dua) instrumen dalam penelitian ini. Kedua instrumen tersebut yaitu kuisioner tentang faktor-faktor yang berhubungan dengan disiplin kerja dan formulir penilaian disiplin kerja. Instrumen yang digunakan dalam penelitian ini telah dilakukan uji validitas dan reliabilitas dan semua item pertanyaan dinyatakan hasilnya valid.

\section{HASIL PENELITIAN Analisis Unvariat}

Tabel 1 :

Analisis Univariat Faktor-Faktor yang Berhubungan dengan Disiplin Kerja

\begin{tabular}{lccc}
\hline \multicolumn{1}{c}{ Variabel } & Kategori & Jumlah & $(\%)$ \\
Tujuan Pekerjaan & Kurang Baik & 13 & 15,5 \\
& Baik & 71 & 84,5 \\
Kemampuan & Kurang Baik & 32 & 38,1 \\
Karyawan & Baik & 52 & 61,9 \\
Keteladana & Kurang Baik & 18 & 21,4 \\
Pemimpin & Baik & 66 & 78,6 \\
Balas Jasa/ Imbalan & Kurang Sesuai & 28 & 33,3 \\
& Sesuai & 56 & 66,7 \\
Sanksi Hukuman & Kurang Sesuai & 35 & 41,7 \\
& Sesuai & 49 & 58,3 \\
Disiplin Kerja & Rendah & 33 & 39,3 \\
& Tinggi & 51 & 60,7 \\
\hline
\end{tabular}

Berdasarkan tabel 1 menunjukkan bahwa mayoritas responden memiliki persepsi baik akan tujuan pekerjaan yaitu sebanyak 71 responden (84,5\%). Dari 84 responden maayoritas responden memiliki persepsi baik terhadap kemampuan pekerjaan yaitu sebanyak 52 responden (61,9\%). Mayoritas responden memiliki persepsi baik terhadap keteladanan pemimpin yaitu sebanyak 66 orang responden $(78,4 \%)$. Mayoritas responden memiliki persepsi bahwa balas jasa/imbalan yang diterima sudah sesuai yaitu sebanyak 56 responden $(66,7 \%)$. Mayoritas responden memiliki persepsi bahwa sanksi/hukuman yang yang diterapkan sudah sesuai yaitu sebanyak 49 responden $(58,3 \%)$. Mayoritas responden memiliki disiplin kerja tinggi sebanyak 51 responden $(60,7 \%)$.

\section{Analisis Bivariat}

\section{Tujuan Pekerjaan}

Tabel 2

Tujuan Pekerjaan

\begin{tabular}{ccccccc}
\hline \multirow{2}{*}{ Tujuan } & \multicolumn{2}{c}{ Rendah } & \multicolumn{2}{c}{ Tisiplin Kerja } & \multicolumn{2}{c}{ Total } \\
& $\mathrm{n}$ & $\%$ & $\mathrm{n}$ & $\%$ & $\mathrm{n}$ & $\%$ \\
\hline Kurang Baik & 7 & 8,3 & 6 & 7,1 & 13 & 100 \\
Baik & 26 & 31,0 & 45 & 53,6 & 71 & 100 \\
Jumlah & 33 & 39,3 & 51 & 60,7 & 84 & 100 \\
\hline
\end{tabular}

Berdasarkan tabel 2 menunjukkan bahwa 13 responden yang memiliki persepsi kurang baik terhadap pemahaman akan tujuan pekerjaan, terdapat 6 responden $(7,1 \%)$ yang memiliki disiplin kerja tinggi. Sedangkan dari 71 responden yang memiliki persepsi yang baik terhadap pemahaman akan tujuan pekerjaan, terdapat 45 responden $(53,6 \%)$ 
yang memiliki disiplin kerja tinggi $(95 \% \mathrm{CI})$. Berdasarkan uji uji chi-square, didapatkan hasil yang tidak bermakna $(\mathrm{p}=0,390 ; \alpha=0,05)$.

\section{Kemampuan Karyawan}

Tabel 3 :

Kemampuan Karyawan

\begin{tabular}{|c|c|c|c|c|c|c|}
\hline \multirow{3}{*}{ Kemampuan } & \multicolumn{4}{|c|}{ Disiplin Kerja } & \multirow{2}{*}{\multicolumn{2}{|c|}{ Total }} \\
\hline & \multicolumn{2}{|c|}{ Rendah } & \multicolumn{2}{|c|}{ Tinggi } & & \\
\hline & $\mathrm{n}$ & $\%$ & $\mathrm{n}$ & $\%$ & $\mathrm{n}$ & $\%$ \\
\hline Kurang Baik & 15 & 17,9 & 17 & 20,2 & 32 & 100 \\
\hline Baik & 18 & 17,9 & 34 & 40,5 & 52 & 100 \\
\hline Jumlah & 33 & 39,3 & 51 & 60,7 & 84 & 100 \\
\hline
\end{tabular}

Berdasarkan tabel 3 terdapat 17 responden (20,2\%) yang memiliki disiplin kerja tinggi. Sedangkan dari 52 responden yang memiliki persepsi yang baik terhadap kemampuan yang dimiliki dalam melaksanakan pekerjaannya. terdapat 34 responden $(40,5 \%)$ yang memiliki disiplin kerja tinggi $(95 \% \mathrm{CI})$. Berdasarkan uji uji chi-square, didapatkan hasil yang tidak bermakna $(\mathrm{p}=0,375 ; \alpha=0,05)$.

\section{Keteladanan Pemimpin}

Tabel 4

Keteladanan Pemimpin

\begin{tabular}{ccccccc}
\hline \multirow{2}{*}{$\begin{array}{c}\text { Keteladanan } \\
\text { Pemimpin }\end{array}$} & $\mathrm{n}$ & $\%$ & $\mathrm{n}$ & $\%$ & $\mathrm{n}$ & $\%$ \\
& 12 & 14,3 & 6 & 7,1 & 18 & 100 \\
Kurang Baik & 21 & 25,0 & 45 & 53,6 & 66 & 100 \\
Baik & 33 & 39,3 & 51 & 60,7 & 84 & 100 \\
Jumlah & & & & & \multicolumn{2}{c}{ Tinggi } \\
\hline
\end{tabular}

Berdasarkan tabel 4 terdapat 6 responden $(7,1 \%)$ yang memiliki disiplin kerja tinggi. Sedangkan dari 66 responden yang memiliki persepsi yang baik terhadap keteladanan pimpinan, terdapat 45 responden $(53,6 \%)$ yang memiliki disiplin kerja tinggi (95\% CI). Berdasarkan uji uji chi-square, didapatkan hasil yang bermakna $(\mathrm{p}=0,016$; $\alpha=0,05)$.

\section{Balas Jasa/Imbalan}

Tabel 5

Balas Jasa/Imbalan

\begin{tabular}{ccccccc}
\hline \multirow{2}{*}{ Balas Jasa/Imbalan } & \multicolumn{2}{c}{ Rendah } & \multicolumn{2}{c}{ Tinggi } & \multicolumn{2}{c}{ Total } \\
& $\mathrm{n}$ & $\%$ & $\mathrm{n}$ & $\%$ & $\mathrm{n}$ & $\%$ \\
\hline Kurang Sesuai & 19 & 22,6 & 9 & 10,7 & 28 & 100 \\
Sesuai & 14 & 16,7 & 42 & 50,0 & 56 & 100 \\
Jumlah & 33 & 39,3 & 51 & 60,7 & 84 & 100 \\
\hline
\end{tabular}

Berdasarkan tabel 5 terdapat 9 responden $(10,7 \%)$ yang memiliki disiplin kerja tinggi. Sedangkan dari 56 responden yang memiliki persepsi bahwa balas jasa/imbalan yang diterima sudah sesuai, terdapat 42 responden $(50,0 \%)$ yang memiliki disiplin kerja 
tinggi $(95 \% \mathrm{CI})$. Berdasarkan uji uji chi-square, didapatkan hasil yang bermakna $(\mathrm{p}=0,000 ; \alpha=0,05)$.

\section{Sanksi Hukuman}

Tabel 6

Sanksi Hukuman

\begin{tabular}{ccccccc}
\hline & \multicolumn{2}{c}{ Disiplin Kerja } & \multicolumn{2}{c}{ Total } \\
Sanksi Hukum & \multicolumn{2}{c}{ Rendah } & \multicolumn{2}{c}{ Tinggi } & \multicolumn{2}{c}{${ }^{2}$} \\
& $\mathrm{n}$ & $\%$ & $\mathrm{n}$ & $\%$ & $\mathrm{n}$ & $\%$ \\
Kurang Sesuai & 20 & 23,8 & 15 & 17,9 & 35 & 100 \\
& & & & & & \\
Sesuai & 13 & 15,5 & 36 & 42,9 & 49 & 100 \\
Jumlah & 33 & 39,3 & 51 & 60,7 & 84 & 100 \\
\hline
\end{tabular}

Berdasarkan tabel 6 terdapat 15 responden $(17,9 \%)$ yang memiliki disiplin kerja tinggi. Sedangkan dari 49 responden yang memiliki persepsi bahwa sanksi hukuman yang diterapkan sudah sesuai, terdapat 36 responden $(42,9 \%)$ yang memiliki disiplin kerja tinggi (95\% CI). Berdasarkan uji uji chi-square, didapatkan hasil yang bermakna $(p=0,009 ; \alpha=0,05)$.

\section{PEMBAHASAN}

\section{Tujuan Pekerjaan}

Berdasarkan hasil analisis univariat, didapatkan bahwa hampir seluruh karyawan penunjang medis dan non medis Rumah Sakit Khusus Jiwa Soeprapto Provinsi Bengkulu memiliki pemahaman yang baik akan tujuan dari pekerjaannya, sehingga menyebabkan pemahaman akan tujuan pekerjaan tidak bermakna secara statistik dengan disiplin kerja karyawan. Hasil penelitian ini sejalan dengan hasil penelitian Fachri (2010) yang menyatakan bahwa tidak adanya hubungan yang signifikan antara tujuan dengan disiplin kerja karyawan.

Hasil penilaian rekapitulasi kuesioner tujuan pekerjaan, nilai kuesioner terendah untuk ketegori tujuan pekerjaan yaitu point 2 (tidak setuju) untuk pertanyaan no 2 " saya mengetahui betul apa yang ingin dicapai dari pekerjaan saya" dengan alasan mereka hanya melihat tujuan pekerjaan secara umum bukan melihat tujuan pekerjaan secara khusus dan mereka tidak terlalu memperhatikan tujuan dari pekerjaannya karena selama ini mereka mengerjakan pekerjaan hanya berdasarkan perintah dan mereka merasa bahwa pekerjaan mereka adalah kewajiban yang harus dilakukan dan beberapa responden yang tidak mengetahui betul akan pencapaian dari pekerjaannya dikarenakan beberapa responden memiliki tingkat pendidikan rendah yaitu Sekolah Menengah Atas (SMA).

Berdasarkan wawancara tidak terstruktur dan observasi langsung yang dilakukan peneliti, didapatkan informasi bahwa beberapa karyawan penunjang medis dan non medis Rumah Sakit Khusus Jiwa Soeprapto Provinsi Bengkulu tidak terlalu memperhatikan tujuan dari pekerjaannya karena selama ini mereka melakukan pekerjaan yang rutin dilakukan. 


\section{Kemampuan Karyawan}

Hasil penelitian ini sejalan dengan hasil penelitian Ferri (2009) yang menyatakan bahwa kemampuan karyawan dalam melaksanakan pekerjaannya tidak berhubungan dengan disiplin kerja karyawan.

Pada beberapa penelitian sebelumnya juga didapatkan adanya hubungan yang signifikan anntara kemampuan dengan disiplin kerja karyawan. Berdasarakan hasil penelitian yang dilakukan oleh Amalia (2013) terbukti bahwa faktor kemampuan memiliki hubungan yang signifikan terhadap disiplin kerja menurut Amalia, karyawan yang memiliki kemampuan untuk melaksanakan pekerjaannya, memiliki peluang lebih besar dalam berdisiplin kerja dibandingkan dengan karyawan yang kurang memiliki kemampuan untuk melaksanakan pekerjaannya.

Perbedaan hasil pada penelitian ini disebabkan oleh beberapa hal, diantaranya karena sebagian besar pekerjaan yang dilakukan oleh karyawan non medis Rumah Sakit Khusus Jiwa adalah pekerjaan-pekerjaan yang rutin dilakukan sehingga tidak memerlukan kemapuan yang sulit dan beragam dalam melaksanakannya. Dengan demikian, para karyawan penunjang medis dan non medis Rumah Sakit Khusus Jiwa dapat melaksanakan pekerjaannya dan dapat menerapkan disiplin kerja dengan baik karena sudah terbiasa melakukan pekerjaan tersebut, sehingga faktor kemampuan kurang berpengaruh terhadap disiplin kerja karyawan.

\section{Keteladanan Pemimpin}

Hasil penelitian ini sejalan dengan hasil penelitian Fachri (2010) yang menyatakan bahwa ada hubungan yang signifikan antara keteladanan pimpinan dengan disiplin kerja karyawan. Fachri berpendapat bahwa keteladanan pimpinan memiliki peranan dalam membentuk disiplin kerja bawahannya. Keteladanan pimpinan dapat dijadikan pedoman dalam meningkatkan disiplin pegawai.

Hasil penelitian Sadiah (2015) juga menyatakan bahwa keteladanan pemimpin perpengaruh terhadap disiplin kerja karyawan.

Variabel-variabel yang masuk dalam faktor ini adalah pimpinan-piminan karyawan penunjang medis dan non medis di Rumah Sakit Khusus Jiwa selalu datang dan pulang tepat waktu, pimpinan tidak pernah meninggalkan pekerjaan pada jam kerja. Sehingga keteladanan pemimpin dijadikan contoh dan panutan oleh karyawan dengan kata lain para karyawan akan ikut berdisiplin jika atasan atau para pimpinan mereka juga berdisiplin, keteladanan pemimpin juga dapat dijadikan pedoman dalam meningkatkan disiplin kerja karyawan penunjang medis dan non medis di Rumah sakit Khusus Jiwa Soeprapto Provinsi Bengkulu.

\section{Balas Jasa/Imbalan}

Hasil penelitian yang dilakukan Maristiana (2008) menyatakan bahwa disiplin kerja karyawan berhuungan dengan balas jasa. Dengan kata lain, pemberian balas jasa atau imbalan yang mencukupi, sedikit banyak akan membantu karyawan untuk bekerja dengan baik dan tekun sehingga mereka dapat berdisiplin dengan baik. Karena dengan penerimaan balas jasa yang sesuai, kebutuhan primer mereka akan dapat terpenuhi. Jadi, balas jasa bereran penting untuk menciptakan disiplin kerja karyawan.

Apabila balas jasa/ imbalan yang diberikan sesuai maka mempengaruhi tingkat disiplin kerja karyawan adapun variabel-variabel yang masuk dalam faktor balas jasa/imbalan di Rumah Sakit Khusus Jiwa Soeprapto Provinsi Bengkulu adalah pendapatan gaji pokok Rp 1.500.000 - Rp 2.000.000 (Tingkat pendidikan Diploma dan 
Sarjana), Rp 2.500.000 - Rp 4.000.000 (Tingkat pendidikan Magister) instensif (Rp $800.000)$ tunjangan resiko ( $\mathrm{Rp} 250.000,00)$ dan tunjangan pensiun.

Berdasarkan karakteristik responden, pendidikan dan masa kerja berkaitan dengan faktor balas jasa. Pendidikan berkaitan dengan faktor balas jasa dimana apabila pendidikan seseorang itu tinggi maka balas jasa karyawan lebih tinggi dibandingkan seseorang yang berpindidikan rendah.

Sedangkan masa kerja berkaitan dengan faktor balas jasa karena apabila masa kerja seseorang itu lama maka balas jasa jauh lebih tinggi. Dikarenakan karyawan yang memiliki masa kerja lama sudah pernah dilakukan kenaikan gaji, dan instensif yang diberikan lebih besar sehingga pendapatannya cukup tinggi dibandingkan karyawan yang memiliki masa kerja baru (Syari \& Wirda, 2012).

Jadi, balas jasa berperan penting untuk menciptakan kedisiplinan karyawan. Artinya, semakin besar balas jasa semakin baik kedisiplinan karyawan. Sebaliknya, apabila balas jasa kecil, kedisiplinan menjadi rendah karena karyawan sulit untuk berdisiplin baik selama kebutuhan-kebutuhan primernya tidak terpenuhi dengan baik.

\section{Sanksi Hukuman}

Hasil penelitian yang dilakukan oleh Avrianto \& Heriyanto (2012) memiliki hubungan yang signifikan terhadap disiplin kerja. Sanksi hukuman diperlukan dalam meningkatkan kedisiplinan karyawan agar menaati semua peraturan perusahaan atau organisasi rumah sakit.

Hasil penelitian Asniar (2016) juga menyatakan bahwa ada hubungan sanksi hukuman dengan disiplin kerja karyawan. Menurut Asniar Sanksi hukuman, berperan penting dalam memelihara kedisiplinan karyawan. Sanksi hukuman harus ditetapkan berdasarkan pertimbangan logis, masuk akal dan diinformasikan secara jelas kepada semua karyawan. Sanksi hukuman seharusnya tidak terlalu ringan atau terlalu berat agar hukuman itu tetap mendidik karyawan untuk mengubah perilakunya.

Menurut beberapa responden sanksi hukuman yang diberikan kepada karyawan penunjang medis dan non medis yang melanggar disiplin kerja sudah sesuai dengan ketentuan yang berlaku yaitu berupa pemberian sanksi disiplin ringan, sanksi disiplin sedang dan sanksi disiplin berat. Pemberian sanksi disiplin ringan berupa peringatan lisan dan tertulis, pemberian sanksi disiplin sedang yaitu untuk karyawan yang terlambat datang yaitu berupa pemotongan tunjangan resiko $10 \%$ dari $\mathrm{Rp} 250.000$ dan penundaan pemberian tunjangan resiko. Sedangkan untuk sanksi disiplin berat yaitu berupa demosi jabatan yang setingkat lebih rendah dari pekerjaan yang diberikan sebelumnya. Dengan demikian sanksi hukuman yang ditetapkan tersebut, dapat memotivasi karyawankaryawan Rumah Sakit Khusus Jiwa Soeprapto Provinsi Bengkulu untuk meningkatkan disiplin kerjanya.

\section{SIMPULAN}

Ada hubungan yang bermakna antara keteladanan pemimpin, balas jasa dan sanksi hukuman terhadap disiplin kerja. Tidak ada hubungan yang bermakna antara tujuan pekerjaan dan kemampuan karyawan dengan disiplin kerja karyawan penunjang medis dan non medis di Rumah Sakit Khusus Jiwa Soeprapto Provinsi Bengkulu. 


\section{SARAN}

Saran untuk Rumah Sakit Khusus Jiwa Soeprapto Provinsi Bengkulu agar meninjau kembali sistem pemberian kompensasi agar mengandung prinsip keadilan dengan mempertimbangkan faktor internal, perlu perhatian yang lebih dari rumah sakit terhadap tingkat disiplin kerja karyawan khususnya karyawan penunjang medis dan non medis.

Bagi kepala bagian penunjang medis dan non medis agar memaksimalkan peran untuk memberi contoh, mengawasi kedisplinan dan memantau kondisi setiap bawahannya. Menyusun, menganalisa, merumuskan, dan menetapkan standar penilaian disiplin kerja karyawan.

\section{DAFTAR PUSTAKA}

Amalia, H. M. (2013). Analisis Faktor yang Berhubungan dengan Kedisiplinan Waktu Kerja Karyawan Non Medis di Rumah Sakit Bogor Medical Center Tahun 2013. Universitas Indonesia. Diakses pada tanggal 02 April 2017

Anisfuddin, A. (2001). Faktor-Faktor yang Berhubungan dengan Disiplin Waktu Kerja Perawat Puskesmas Wilayah Kecamatan Panti dan Kecamatan Rao Kabupaten Pasaman. Universitas Indonesia. Diakses pada tanggal 02 April 2017

Asniar, J., \& Tina, L. (2016). Faktor-faktor yang Berhubungan dengan Disiplin Kerja Pegawai Puskesmas Puriala Kecamatan Puriala Kabupaten Konawe: 1 - 7. Diakses pada tanggal 11 Juni 2017

Avrianto, A \& Heriyanto, M. (2012). Analisis Disiplin Kerja pada Rumah Sakit Lancang Kuning Pekan Baru Tahun 2012. https://repository.unri.ac.id/handle/123456789/778

Dessler, G. (2012). Manajemen Sumber Daya Manusia. (Eli Tanya, Penerjemah). Jakarta: Indeks

Fachri, H. (2010). Faktor-Faktor yang Mempengaruhi Disiplin Kerja Pegawai di Rumah Sakit RI Pontianak Tahun 2010. Universitas Muhammadiyah Pontianak. Diakses pada tanggal 12 April 2017

Ferri, H. (2009). Pengaruh Disiplin Kerja dan Gaya Kepemimpinan terhadap Kinerja Karyawan di PDHI Yogyakarta. Diakses pada tanggal 12 Juni 2017

Handoko, H. T. (2012). Manajemen Personalia dan Sumber Daya Manusia. Yogyakarta: BPFE-Yogyakarta

Hasibuan, M. S. P. (2013). Manajemen Sumber Daya Manusia, Edisi Revisi. Jakarta: Bumi Aksara

Maristiana, L. (2008). Pengaruh Disiplin Kerja terhadap Produktivitas Kerja Perawat di Rumah Sakit Islam Yogya PDHI Tahun 2008 .[Jurnal]. Diakses pada tanggal 12 Juni 2017

Nurpeni, N. (2010). Pelaksanaan Pengelolaan Sumber Daya Manusia (SDM) dan Hubungan dengan Peningkatan Mutu Rumah Sakit Umum Daerah (RSUD) Selasih Kabupaten Pelalawan Pekanbaru. Diakses pada tanggal 12 Juni 2017

RSKJ. (2015). Profil Rumah Sakit Khusus Jiwa Soeprapto Propinsi Bengkulu

Sadiah, H. (2015). Faktor-Faktor yang Berhubungan dengan Disiplin Perawat Rumah Sakit Dr Adnaan WD Kota Paya Kumbuh Tahun 2015. Universitas Andalas. Diakses pada tanggal 13 September 2017

Sastrohadiwiryo, B. S. (2005). Manajemen Tenaga Kerja Indonesia Pendekatan Administratif dan Operasional. Jakarta: PT. Bumi Aksara 
Syari, W. (2012). Faktor-Faktor yang Berhubungan dengan Disiplin Kerja Karyawan Non Medis di Rumah Sakit Karya Bhakti 2012. Universitas Indonesia. Diakses pada tanggal 02 April 2017 